\title{
Dopamine protects neurons against glutamate-induced excitotoxicity
}

\author{
A Vaarmann ${ }^{1,2,3}$, S Kovac $^{1,3}$, KM Holmström $^{1,3}$, S Gandhi ${ }^{1}$ and AY Abramov ${ }^{*, 1}$
}

Glutamate excitotoxicity is responsible for neuronal death in acute neurological disorders including stroke, trauma and neurodegenerative disease. Loss of calcium homeostasis is a key mediator of glutamate-induced cell death. The neurotransmitter dopamine (DA) is known to modulate calcium signalling, and here we show that it can do so in response to physiological concentrations of glutamate. Furthermore, DA is able to protect neurons from glutamate-induced cell death at pathological concentrations of glutamate. We demonstrate that DA has a novel role in preventing delayed calcium deregulation in cortical, hippocampal and midbrain neurons. The effect of DA in abolishing glutamate excitotoxicity can be induced by DA receptor agonists, and is abolished by DA receptor antagonists. Our data indicate that the modulation of glutamate excitotoxicity by DA is receptor-mediated. We postulate that DA has a major physiological function as a safety catch to restrict the glutamate-induced calcium signal, and thereby prevent glutamate-induced cell death in the brain.

Cell Death and Disease (2013) 4, e455; doi:10.1038/cddis.2012.194; published online 10 January 2013

Subject Category: Neuroscience

Signal transduction within the central nervous system (CNS) is mediated by specific neurotransmitters, whose properties have been studied in detail for several decades. Besides their role in signal transduction, neurotransmitters have been implicated in neurotoxicity.

Neurotoxicity in the mammalian CNS has been linked to glutamate (e.g. see review by Choi ${ }^{1}$ ). Glutamate-induced excitotoxicity has been implicated in neuronal cell death that follows periods of acute neuronal injury as anoxia and reperfusion, and it has been proposed that similar processes may contribute to the neuronal injury in neurodegenerative diseases such as motor neuron disease (for review, see Shaw et al. ${ }^{2}$ ) and Alzheimer's disease (e.g. see Schubert and Piasecki ${ }^{3}$ ).

Neuronal delayed $\mathrm{Ca}^{2+}$ accumulation (delayed calcium deregulation, $\mathrm{DCD}$ ) and mitochondrial membrane depolarization in response to glutamate is a requirement for the progression to cell death ${ }^{1,4-6}$. Exposure of neurons in culture to excitotoxic levels of glutamate results in an initial transient increase in cytosolic calcium concentration $\left[\mathrm{Ca}^{2+}\right]_{\mathrm{c}}$ followed by a delayed sustained rise in $\left[\mathrm{Ca}^{2+}\right]_{\mathrm{C}}(\mathrm{DCD})$, which coincides with a profound collapse of mitochondrial membrane potential and is believed to be an initial trigger for neuronal death. ${ }^{7,8}$ Exposure of neurons in culture to glutamate causes selective neuronal cell death that can be effectively blocked by application of inhibitors of glutamate receptors. ${ }^{9}$ However, glutamate antagonists are significantly less effective against neuronal death in vivo when applied to brain following periods of anoxia and reperfusion and clinical trials of $\mathrm{N}$-methyl-Daspartic acid (NMDA) receptor antagonists remained unsuccessful, suggesting some additional mechanisms apply in the whole brain compared with primary neuronal cultures. $^{10,11}$ A possible explanation for this might be an interaction with other neurotransmitters in the brain, modulating glutamate toxicity in vivo.

One of the major emerging functions of dopamine (DA) is its role in modulating plasticity in the striatum, cortex and hippocampus. In these regions, a significant subpopulation of spines of neurons are simultaneously contacted by both dopaminergic and glutamatergic inputs. ${ }^{12}$ Although NMDA receptors respond specifically to glutamate, there is much evidence to suggest an interaction between NMDA signalling and DA. Thus, it was demonstrated that DA and D2 or D4 receptor activators significantly depressed NMDA receptor currents. ${ }^{13,14}$ It remains to be clarified how this translates to glutamate toxicity and neuronal intracellular calcium changes.

In this study we investigate the interplay between glutamate and DA on calcium regulation in primary neurons from different brain regions. We propose that dopaminergic and glutamatergic neurotransmission may interact, and more specifically, that DA may have the role of 'safety catch' in order to protect neurons from glutamate excitotoxicity.

\section{Results}

DA modulates the effect of low physiological concentrations of glutamate on cytosolic calcium. Application of physiological concentrations of glutamate $(5 \mu \mathrm{M})$ induced a transient increase in cytosolic calcium $\left[\mathrm{Ca}^{2+}\right]_{\mathrm{c}}$ in

\footnotetext{
${ }^{1}$ Department of Molecular Neuroscience, UCL Institute of Neurology, Queen Square, London WC1N 3BG, UK

*Corresponding author: AY Abramov, Department of Molecular Neuroscience, UCL Institute of Neurology, Queen Square, London WC1N 3BG, UK. Tel: + 4420 78373611; Fax: + 4420 78373611; E-mail: a.abramov@ucl.ac.uk

${ }^{2}$ Current address: Department of Pharmacology, University of Tartu, Ravila 19, Tartu 51041, ESTONIA.

${ }^{3}$ These authors contributed equally to this work.

Keywords: glutamate; dopamine; excitotoxicity; calcium

Abbreviations: CNS, central nervous system; DA, dopamine; DCD, delayed calcium deregulation; HBSS, HEPES-buffered salt solution; NMDA, N-methyl-D-aspartic acid; $\mathrm{MAO}$, monoamine oxidase; PI, propidium iodide

Received 30.7.12; revised 25.9.12; accepted 23.11.12; Edited by A Verkhratsky
} 
hippocampal neurons, as measured by fura-2. Removal of glutamate from the media induced recovery of the calcium to basal levels (Figure 1a, $n=67$ ). Application of $5 \mu \mathrm{M}$ DA to hippocampal neurons also induced a small increase in the basal level of $\left[\mathrm{Ca}^{2+}\right]_{c}$ in primary neurons (as previously reported by us and others. ${ }^{15,16}$ Interestingly, further application of $5 \mu \mathrm{M}$ glutamate induced a significantly smaller rise in the $\left[\mathrm{Ca}^{2+}\right]_{\mathrm{c}}$ than that seen with glutamate alone (Figures $1 \mathrm{~b}$ and $\mathrm{c} ; n=87, P<0.001)$. Importantly, there is a dose response effect of the concentration of DA on the modulation of the glutamate-induced calcium response. Lower concentrations of DA in the $0.5-1 \mu \mathrm{M}$ range, attenuated the calcium signal more significantly than higher concentrations of DA $(5 \mu \mathrm{M})$ (Figure 1c). The reducing effect of higher concentrations of DA on glutamate-induced calcium signalling may be masked by the induction of a DA-induced calcium increase. $^{15-17}$

Onset of glutamate-induced DCD differs between different brain regions. It is well established that glutamate toxicity is induced by simultaneously DCD and mitochondrial depolarization, which can be detected only using low-affinity calcium indicators. We therefore measured the appearance of the glutamate-induced DCD in cortical, hippocampal and midbrain neurons using the low-affinity calcium indicator fura-FF. The appearance of DCD in response to $100 \mu \mathrm{M}$ glutamate in midbrain neurons (Figures $2 \mathrm{a}$ and $\mathrm{d}, n=99$ ) was significantly delayed compared with the appearance of DCD in cortical neurons $(3.7 \pm 0.7 \mathrm{~min}$ compared with $11.4 \pm 1.1 \mathrm{~min}$ in midbrain neurons; Figures $2 \mathrm{~b}$ and $\mathrm{d}$, $n=74)$ and hippocampal neurons (4.1 $\pm 0.3 \mathrm{~min}$; Figure $2 \mathrm{~d}$, see also Figure $4 a ; n=101)$. The time of onset of DCD in cells from different brain regions is shown in the histogram (Figure 2d). It is not yet known whether this difference in DCD is due to the regional difference in expression of the NMDA receptor, or whether it is related to the presence of other neurotransmitters such as DA.
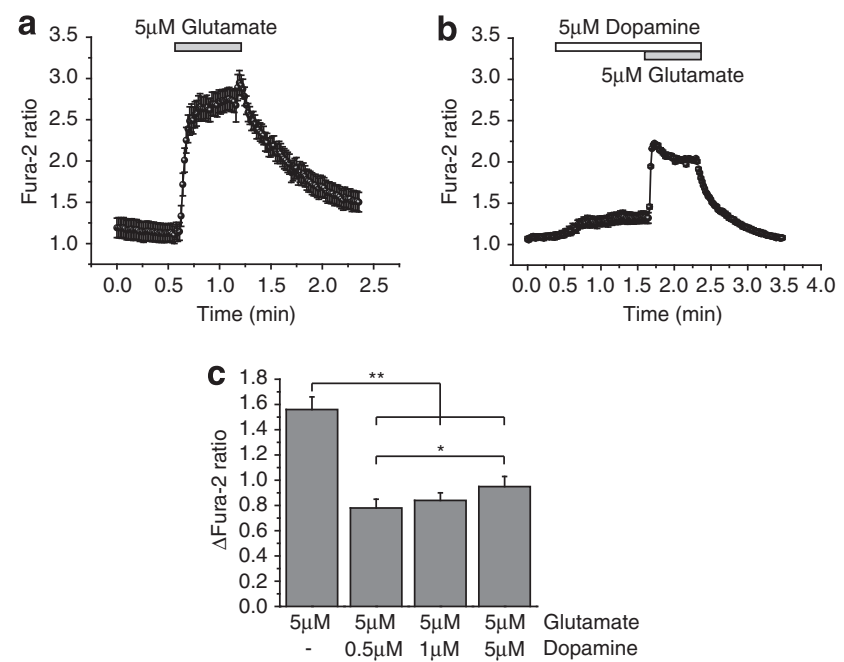

Figure 1 DA modulates the effect of low physiological concentrations of glutamate on $\left[\mathrm{Ca}^{2+}\right]_{\mathrm{c}}$. Short application of $5 \mu \mathrm{M}$ glutamate to hippocampal neurons induced a rise in $\left[\mathrm{Ca}^{2+}\right]_{c}$ (Fura-2 ratio) (a). (b) $5 \mu \mathrm{M}$ DA significantly reduced glutamate-induced calcium signal. (c) Effect of different concentrations of DA on the glutamate induced $\mathrm{Ca}^{2+}$ rise in hippocampal neurons. ${ }^{\star} P<0.05$, ${ }^{*} P<0.001$
DA is able to abolish glutamate-induced DCD. We found that at least in vitro DA was able to not only modulate glutamate-induced $\left[\mathrm{Ca}^{2+}\right]_{\mathrm{c}}$ increase but also attenuate DCD. A very low concentration of $0.5 \mu \mathrm{M}$ DA was established to be the most effective at attenuating the glutamate-induced calcium signal, significantly delaying the onset of DCD in all neurons from all brain regions tested (Figures $2 c$ and d). At such low concentrations, DA is likely to be rapidly metabolized by the enzyme monoamine oxidase (MAO). Therefore, we pretreated the cells with $20 \mu \mathrm{M}$ selegiline in order to inhibit both isoforms of MAO ( $A$ and $B$ ) in neurons and astrocytes. Under these conditions, addition of $0.5 \mu \mathrm{M}$ DA was able to completely abolish the appearance of glutamate-induced DCD (Figure 2e). The initial peak of glutamate-induced increase in $\left[\mathrm{Ca}^{2+}\right]_{c}$ can still be seen, suggesting that DA is only limiting but does not block the calcium influx through the NMDA receptor. Incubation with selegiline alone, had no effect on the glutamate-induced DCD in the absence of DA (Figure 2f). Higher concentrations of DA (5 and $20 \mu \mathrm{M}$ ) were less effective at inhibiting the DCD than lower concentrations (Figure 2d).

DA modulation of glutamate is D2 receptor-mediated. In order to understand the mechanism of DA modulation of the glutamate signal, we used D1-like and D2-like receptor antagonists. The protective effect of DA on DCD was completely abolished in the presence of the D2-like receptor antagonist $(20 \mu \mathrm{M}$ sulpiride) (Figure $3 \mathrm{~b}$ compared with Figure $3 a, n=122)$. The appearance of glutamate-induced DCD in midbrain neurons after application of sulpiride and DA was even earlier than after glutamate alone (Figures $3 b$ and d compared with Figure $2 b$ ). Similarly, the effect of DA on DCD was significantly reduced in the presence of the D1/D5 antagonist $20 \mu \mathrm{M}$ SCH-23390 (Figure 3c, $n=75$ ). The effect of D-receptor antagonists on DCD was observed in hippocampal, cortical and midbrain neurons (Figure 3d). It should be noted that lower concentrations of antagonists $(100 \mathrm{nM})$ did not have an effect on glutamate-induced DCD ( $n=37$ for $100 \mathrm{nM} \mathrm{SCH}-23390 ; n=51$ for $100 \mathrm{nM}$ sulpiride).

To further confirm a receptor-mediated mechanism of DAmediated DCD modulation we used specific agonists for D1 and D2 receptors. Preincubation of hippocampal neurons with specific D2 agonist quinpirole $(10 \mu \mathrm{M})$ significantly delayed the appearance of glutamate-induced DCD (Figure 4b, $n=161$, compared with glutamate alone Figure 4a; $n=101)$. The effect of D1-specific agonists 6-chloro-APB $(10 \mu \mathrm{M})$ on DCD was also significant (Figure $4 \mathrm{c}, n=187)$ but smaller than the effect of D2 agonist. Using lower concentrations of DA agonists (10 nM 6-chloro-APB or $10 \mathrm{nM}$ quinpirole) did not significantly alter the effect of the glutamate-induced DCD, suggesting that in cellular experiments the concentration necessary for effective signalling is in a $10 \mu \mathrm{M}$ range (Supplementary Figure S1).

DA is neuroprotective for glutamate-induced cell death. To investigate long-term effects of DA modulation of glutamate signalling, we measured neuronal death $24 \mathrm{~h}$ after treating cells for $15 \mathrm{~min}$ with $100 \mu \mathrm{M}$ glutamate. Low concentrations of DA $(0.1-5 \mu \mathrm{M})$ were significantly protective against glutamate excitotoxicity in primary neurons. 

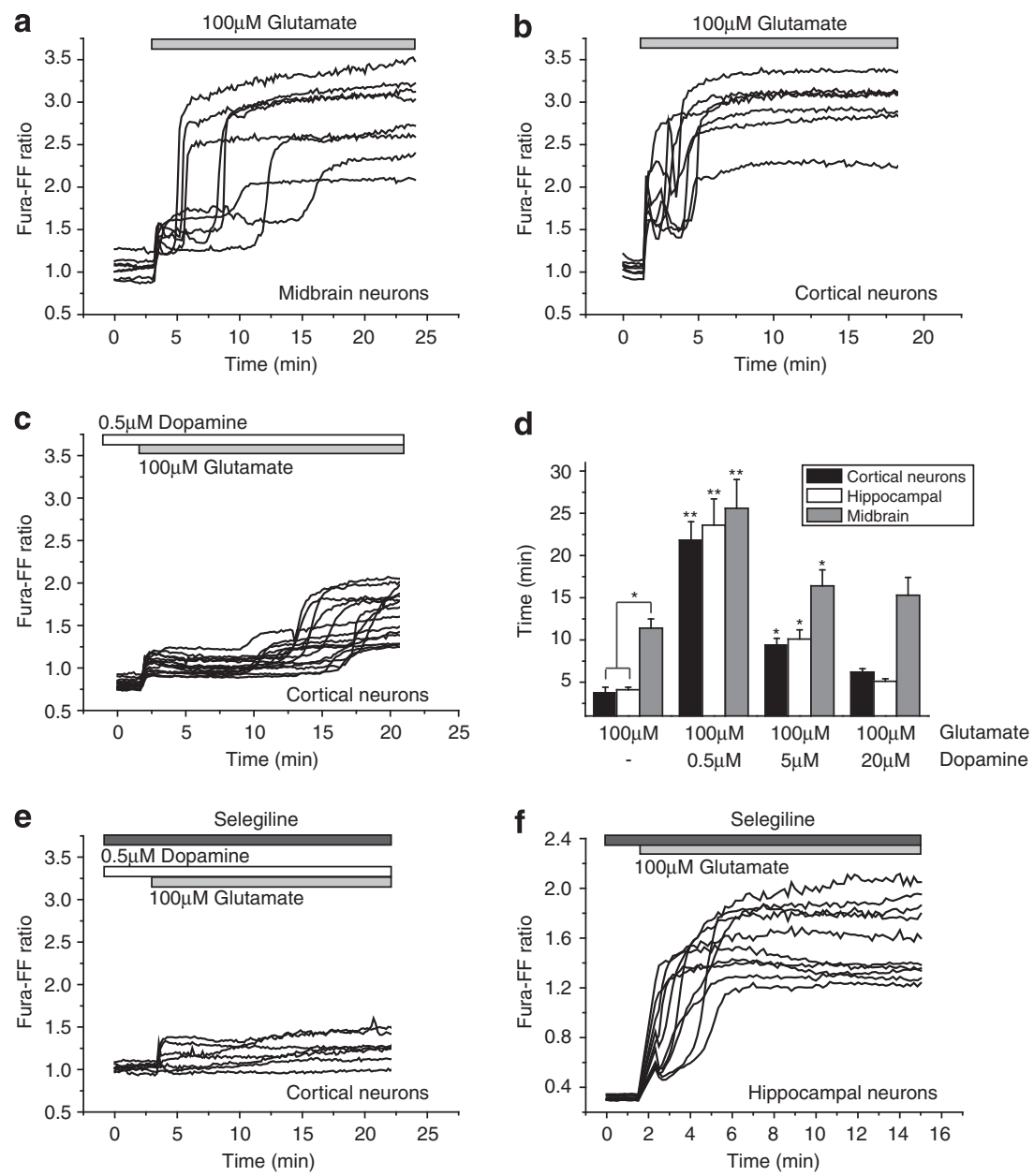

Figure 2 Changes in the $\left[\mathrm{Ca}^{2+}\right]_{\mathrm{C}}$ response to toxic concentrations of glutamate. Kinetic measurements of changes in $\left[\mathrm{Ca}^{2+}\right]_{\mathrm{C}}(\mathrm{Fura}-\mathrm{FF}$ ratio) from single neurons in

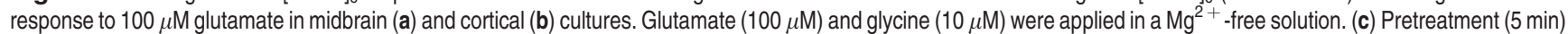
of cortical neurons with $0.5 \mu \mathrm{M} \mathrm{DA}$ inhibits appearance of $\mathrm{DCD}$ in response to glutamate. Histogram showing the time from the application of glutamate until the start of the appearance of $D C D$ in neurons from different brain regions in response to $100 \mu \mathrm{M}$ glutamate $\left(+10 \mu \mathrm{M}\right.$ glycine in $\mathrm{Mg}^{2+}{ }_{\text {-free}}$ ) with varying concentrations of $D A$ (d). ${ }^{*} P<0.05$, ${ }^{* \star} P<0.001$. (e) Co-application of $20 \mu \mathrm{M}$ selegiline and $0.5 \mu \mathrm{M}$ DA 5 min before the experiment completely inhibited the glutamate-induced DCD. (f) Preincubation (5 min) with selegiline did not prevent the glutamate-induced DCD

Exposure of cells for $15 \mathrm{~min}$ to $100 \mu \mathrm{M}$ glutamate-induced neuronal death in $83.9 \pm 6.4 \%$ of cortical neurons, $n=4$ experiments. Co-application of 1-2 $\mu \mathrm{M}$ DA with glutamate reduced the number of dead neurons in cortical culture to $26.4 \pm 1.4 \%(n=4 ; P<0.001$; Figure $5 a)$. Of note, midbrain neurons are inherently less vulnerable to glutamate-induced cell death than cortical neurons, and the addition of DA also significantly attenuated cell death from $51.1 \pm 1.7 \%$ of midbrain neurons to $11.7 \pm 2.4 \% \quad(n=4 ; \quad P<0.001$; Figure $5 a)$. Interestingly, higher concentrations of DA (10 and $20 \mu \mathrm{M})$ were less effective than $1 \mu \mathrm{M}(n=5$ experiments for both 10 and $20 \mu \mathrm{M}$ DA; Figure $5 \mathrm{a}$ ) correlating with our experiments on the effect of DA on glutamate-induced calcium deregulation. It should be noted that selegiline $(20 \mu \mathrm{M}, n=4)$ alone was not protective against glutamateinduced excitotoxicity $(76 \pm 4.7 \%$ compared with $83.9 \pm 6.4 \%$ in glutamate only for cortical neurons).

The protective effect of DA on glutamate-induced cell death was mediated to various degrees through both D1- and D2-like receptors in cortical neurons. The D1/D5 receptor antagonist SCH-23390 $(20 \mu \mathrm{M})$ blocked the protective effect of DA on cell death, while there was no statistically significant inhibition by the D2-like receptor antagonist sulpiride $(20 \mu \mathrm{M})$ (from $26.4 \pm 1.4 \%$ to $41.4 \pm 2.3$ for SCH-23390, $n=5$; $P<0.05$ and to $37.2 \pm 2.7$ for sulpiride, $n=5$; Figure $5 \mathrm{~b}$ ). These data strongly indicate that DA protects neurons against glutamate-induced cell death through a receptor-operated mechanism.

\section{Disscussion}

We report for the first time that DA is able to inhibit glutamate excitotoxicity and neuronal death by preventing the onset of DCD. As glutamate and DA frequently work together in signal transmission in the brain, this new role for DA has implications for health and disease.

Glutamate is the major excitatory neurotransmitter in the mammalian CNS. Neurons respond to excitatory stimuli by initiating calcium entry through plasma membrane channels. Glutamate induces a calcium signal to a varying degree 

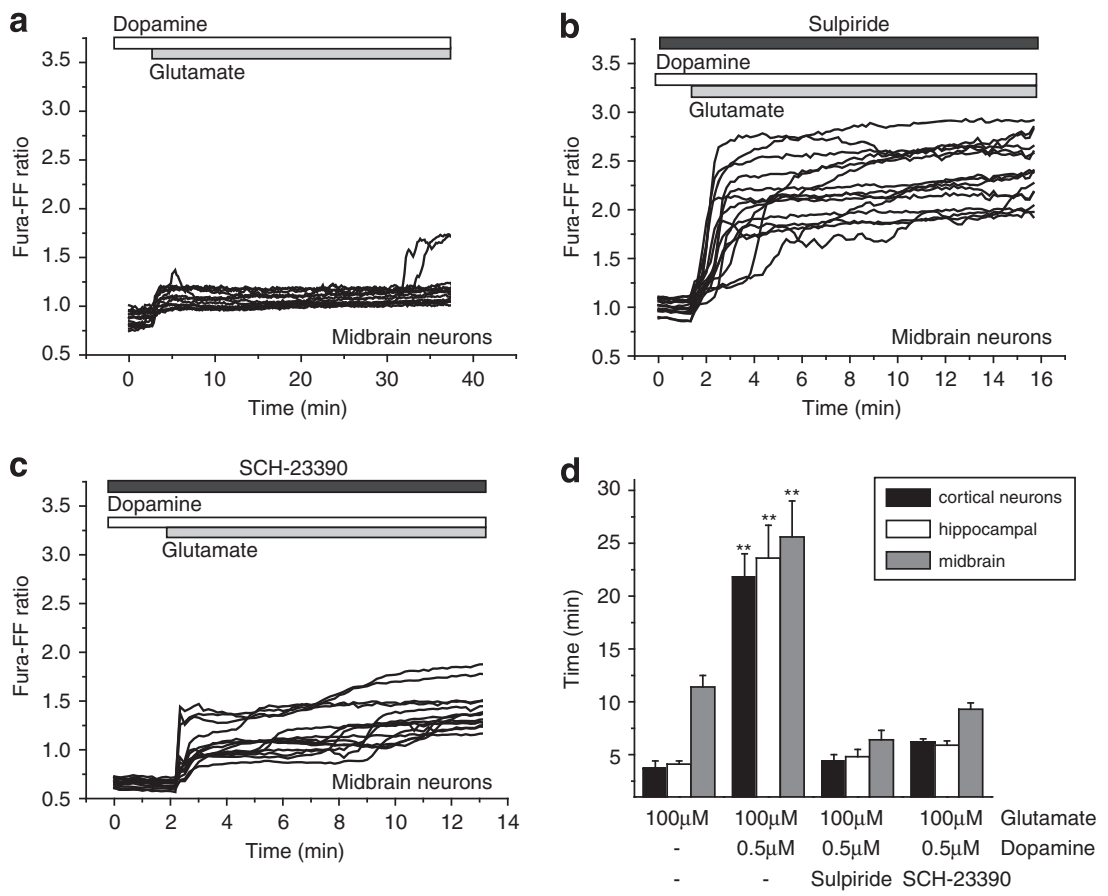

Figure 3 Effect of DA and DA antagonists on glutamate-induced $\left[\mathrm{Ca}^{2+}\right]_{c}$ changes in primary neurons. (a) $0.5 \mu \mathrm{M} \mathrm{DA}$ inhibits appearance of DCD in midbrain neurons in response to $100 \mu \mathrm{M}$ glutamate ( $+10 \mu \mathrm{M}$ glycine in $\mathrm{Mg}^{2+}$-free). Preincubation ( $5 \mathrm{~min}$ ) of $20 \mu \mathrm{M}$ sulpiride (b) or $20 \mu \mathrm{M} \mathrm{SCH}-23390$ (c) eliminates protective effect of DA against DCD. (d) The effect of $0.5 \mu \mathrm{M}$ DA alone and in combination with $20 \mu \mathrm{M}$ sulpiride or $20 \mu \mathrm{M} \mathrm{SCH}-23390$ on time of appearance of glutamate-induced DCD. Histogram represent the time taken from application of $100 \mu \mathrm{M}$ glutamate to the beginning of the $\mathrm{DCD}$ in neurons from the different brain region. ${ }^{* *} P<0.001$
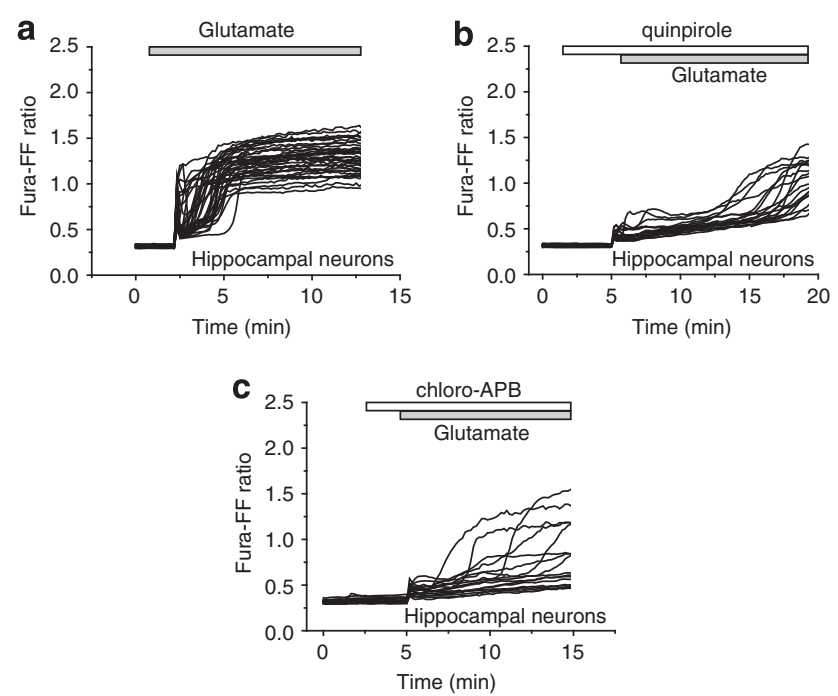

Figure 4 Effect of DA agonists on glutamate-induced $\left[\mathrm{Ca}^{2+}\right]_{c}$ changes in primary neurons. (a) $100 \mu \mathrm{M}$ glutamate increase $\left[\mathrm{Ca}^{2+}\right]_{\mathrm{c}}$ in primary hippocampal neurons. Pretreatment ( $5 \mathrm{~min}$ ) of hippocampal neurons with $10 \mu \mathrm{M}$ quinprole (b) or $10 \mu \mathrm{M}$ chloro-APB (c) changed the shape of the glutamate-induced $\mathrm{Ca}^{2+}$ signal

through both NMDA-R channels and voltage-dependent calcium channels in neuronal cultures. ${ }^{18,19}$

DA itself is able to produce a calcium signal within cells that may be receptor-mediated, causing release from intracellular calcium stores (in neurons- ${ }^{16}$ or receptor-independent in astrocytes, ${ }^{20}$ or possibly due to opening of voltage-dependent calcium channels inducing exogenous calcium influx. ${ }^{15} \mathrm{We}$ demonstrate that preincubation with DA results in inhibition of the glutamate-induced calcium signal. This appears to be dose-dependent, and lower concentrations of DA inhibit the glutamate-induced calcium signal more significantly than higher concentrations. This dopaminergic modulation of physiological glutamate signalling is in agreement with previous reports in the literature, and suggests that the interaction of DA and glutamate has important functions in calcium signalling. ${ }^{13,14}$ The absence of DA caused by striatal DA depletion such as that occurring in Parkinson's disease may therefore result in uninhibited glutamate-induced calcium signalling and this may underlie the clinical hyperkinetic features such as tremor in the disease. Interestingly, we see much delayed DCD in midbrain-derived neurons compared with hippocampal or cortical neurons. Our finding is in agreement with previous report than DA depletion in transgenic models with labelled medium spiny neurons subpopulations results in a loss of glutamatergic synapses and shrinking of the dendritic tree of striatopallidal neurons, resulting in an overall reduction in glutamate input. ${ }^{21,22}$

DCD describes the second phase of a typical biphasic cytosolic calcium response to glutamate exposure. In chronic glutamate exposure DCD is the point at which there is latent loss of calcium homeostasis. The nature of the secondary rise in calcium during DCD is either due to a reduction in the capacity of the calcium efflux mechanisms or a latent activation of plasma membrane ion channels or a combination of both ${ }^{23}$ that lead to an energy collapse of the neuron. ${ }^{8,24}$

In this study we demonstrate a new role for DA in the DA/ glutamate crosstalk. We show that low concentrations of DA 

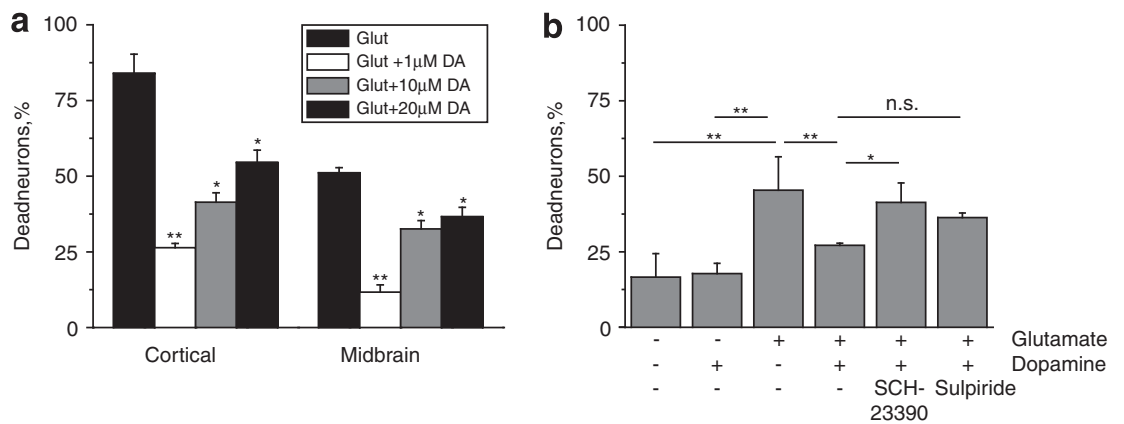

Figure 5 Dependence of glutamate-induced neuronal cell death on the presence of DA. (a) The viability of primary cortical and midbrain neurons was measured $24 \mathrm{~h}$ after a $15 \mathrm{~min}$ application of $100 \mu \mathrm{M}$ glutamate in $10 \mu \mathrm{M}$ glycine, $\mathrm{Mg}^{2+}$-free medium, in the presence of either $0,1,10$ or $20 \mu \mathrm{M} \mathrm{DA}$, using PI fluorescence. Dead cells were counted with respect to total number of cells present, identified by staining nuclei with Hoechst 33342 . (b) Cell death was further measured in cortical neurons after cells were pretreated for 10 min with either DA $(1 \mu \mathrm{M})$ alone or in combination with $20 \mu \mathrm{M} \mathrm{SCH}-23390$ or $20 \mu \mathrm{M}$ sulpiride before application of $100 \mu \mathrm{M}$ glutamate. DA and the inhibitors were left in the medium during the 15 min glutamate exposure. ${ }^{* *} P<0.05$, ${ }^{*} P<0.001$; n.s., not significant

are able to effectively abolish the DCD induced by glutamate excitotoxicity. Prevention of the loss of calcium homeostasis seen in DCD is more effective at low concentrations of DA rather than high concentrations of DA, possibly due to the calcium increase activated by DA itself at higher concentrations. ${ }^{15-17}$ It should be noted that the concentration of intracellular calcium depends not only on calcium influx by NMDARs and voltage-dependent calcium channels but also on efflux mechanisms such as $\mathrm{Na}^{+} / \mathrm{Ca}^{2+}$ exchangers. Calcium may also gain access to the cytosol through release from intracellular stores such as endoplasmic reticulum and mitochondria. Therefore, it may be possible that DA exerts a role in other calcium transport processes to protect against DCD.

In addition to modulating DCD, we further confirm that abolishing glutamate-induced DCD by low concentrations of $D A$, results in reduced glutamate-induced cell death measured at $24 \mathrm{~h}$. To our knowledge, a neuroprotective action of DA in preventing neuronal death induced by excessive glutamate stimulation has not been shown before.

Our findings have major implications in disease. Massively elevated levels of glutamate are seen in the ischaemic core after stroke and this triggers overwhelming NMDA stimulation, leading to loss of ion homeostasis, cell swelling and necrotic death. ${ }^{25}$ Microdialysis of human brain tissue after traumatic brain injury shows sustained (days to weeks) rise in glutamate concentrations in the range of $50-100 \%$ increase. ${ }^{26}$ To date, there has been little success with neuroprotective strategies in preventing cell death following ischaemic stroke. In order to rescue neurons in the penumbra of an acute stroke, it may be worth considering the importance of DA in preventing glutamate excitotoxicity.

\section{Materials and Methods}

Cell culture. Mixed cultures of hippocampal, cortical and midbrain neurons and glial cells were prepared as described previously ${ }^{15}$ with modifications, from Sprague-Dawley rat pups 2-4 days postpartum (UCL breeding colony). Hippocampi, cortex and midbrain were removed into ice-cold HEPES-buffered salt solution (HBSS) $(\mathrm{Ca} 2+, \mathrm{Mg} 2+-$-free, Gibco-Invitrogen, Paisley, UK). The tissue was minced and trypsinised $\left(0.1 \%\right.$ for $15 \mathrm{~min}$ at $\left.37^{\circ} \mathrm{C}\right)$, triturated and plated on poly-D-lysine-coated coverslips and cultured in Neurobasal medium (GibcoInvitrogen) supplemented with B-27 (Gibco-Invitrogen) and $2 \mathrm{mM}$ L-glutamine. Cultures were maintained at $37^{\circ} \mathrm{C}$ in a humidified atmosphere of $5 \% \mathrm{CO}_{2}$ and $95 \%$ air, media changed twice a week. To avoid the age dependence of the $\mathrm{DCD},{ }^{8}$ we used cells after 12-15 days in vitro in all experiments. Neurons were easily distinguishable from glia: they appeared phase bright, had small smooth rounded somata and distinct processes, and lay just above the focal plane of the glial layer (Supplementary Figure 2).

Imaging $\left[\mathrm{Ca}^{2+}\right]_{\mathrm{c}}$. Hippocampal, cortical and midbrain neurons were loaded for $30 \mathrm{~min}$ at room temperature with $5 \mu \mathrm{M}$ fura-FF AM or $5 \mu \mathrm{M}$ fura-2 $\mathrm{AM}$ and $0.005 \%$ Pluronic in HBSS composed of $(\mathrm{mM}): 156 \mathrm{NaCl}, 3 \mathrm{KCl}, 2 \mathrm{MgSO}_{4}, 1.25$ $\mathrm{KH}_{2} \mathrm{PO}_{4}, 2 \mathrm{CaCl}_{2}, 10$ glucose and 10 HEPES, pH adjusted to 7.35 with $\mathrm{NaOH}$.

Fluorescence measurements were obtained on an epifluorescence inverted microscope equipped with $\mathrm{a} \times 20$ fluorite objective. $\left[\mathrm{Ca}^{2+}\right]_{\mathrm{c}}$ was monitored in single cells using excitation light provided by a Xenon arc lamp, the beam passing monochromator centred at 340 and $380 \mathrm{~nm}$ (Cairn Research, Kent, UK). Emitted fluorescence light was reflected through a $515 \mathrm{~nm}$ long-pass filter to a cooled CCD camera (Retiga, Qlmaging, Surrey, BC, Canada) and digitized to 12 bit resolution. All imaging data were collected and analysed using software from Andor (Belfast, UK). Traces, obtained using the cooled CCD imaging system, are presented as the ratio of excitation at 340 and $380 \mathrm{~nm}$, both with emission at $>515 \mathrm{~nm}$. The time for DCD was measured as the time taken from the addition of glutamate until the start of the calcium increase.

Toxicity experiments. For toxicity assays cells were exposed to $20 \mu \mathrm{M}$ propidium iodide (PI) and $4.5 \mu \mathrm{M}$ Hoechst 33342 (Molecular Probes, Eugene, OR, USA) for $30 \mathrm{~min}$ before imaging. The PI is excluded from viable cells and exhibits a red fluorescence following a loss of membrane integrity, while the Hoechst 33342 labels all nuclei blue. This allows expression of the number of dead (red stained) cells as a fraction of the total number of nuclei counted. Using phase contrast optics, a bright field image allowed identification of neurons, which look quite different to the flatter glial component and also lie in a different focal plane, above the glial layer. A total number of 100-300 neurons were counted in 4-5 fields of each coverslip. Each experiment was repeated four or more times using separate cultures.

Statistical analysis. Statistical analysis was performed with the aid of Origin 8 (Microcal Software Inc., Northampton, MA, USA) software. Means expressed \pm S.E.M.

\section{Conflict of Interest}

The authors declare no conflict of interest.

Acknowledgements. This work was supported by the Wellcome/MRC Parkinson's Disease Consortium grant to UCL/loN; AYA is Parkinson's UK Senior Research Fellow.

1. Choi DW. Calcium and excitotoxic neuronal injury. Ann N Y Acad Sci 1994; 747: 162-171.

2. Shaw CE, al-Chalabi A, Leigh N. Progress in the pathogenesis of amyotrophic lateral sclerosis. Curr Neurol Neurosci Rep 2001; 1: 69-76. 
3. Schubert D, Piasecki D. Oxidative glutamate toxicity can be a component of the excitotoxicity cascade. J Neurosci 2001; 21: 7455-7462.

4. Vergun O, Keelan J, Khodorov BI, Duchen MR. Glutamate-induced mitochondrial depolarisation and perturbation of calcium homeostasis in cultured rat hippocampal neurones. J Physiol 1999; 519(Pt 2): 451-466.

5. Stout AK, Raphael HM, Kanterewicz BI, Klann E, Reynolds IJ. Glutamate-induced neuron death requires mitochondrial calcium uptake. Nat Neurosci 1998; 1: 366-373.

6. Abramov AY, Duchen MR. Mechanisms underlying the loss of mitochondrial membrane potential in glutamate excitotoxicity. Bba-Bioenergetics 2008; 1777: 953-964.

7. Stout AK, Reynolds IJ. High-affinity calcium indicators underestimate increases in intracellular calcium concentrations associated with excitotoxic glutamate stimulations. Neuroscience 1999; 89: 91-100.

8. Abramov AY, Duchen MR. Impaired mitochondrial bioenergetics determines glutamateinduced delayed calcium deregulation in neurons. Biochim Biophys Acta 2010; 1800: 297-304.

9. Michaels RL, Rothman SM. Glutamate neurotoxicity in vitro: antagonist pharmacology and intracellular calcium concentrations. J Neurosci 1990; 10: 283-292.

10. Lai TW, Shyu WC, Wang YT. Stroke intervention pathways: NMDA receptors and beyond. Trends Mol Med 2011; 17: 266-275.

11. Rothman SM, Olney JW. Excitotoxicity and the NMDA receptor-still lethal after eight years. Trends Neurosci 1995; 18: 57-58.

12. Kotter R. Postsynaptic integration of glutamatergic and dopaminergic signals in the striatum. Prog Neurobiol 1994; 44: 163-196.

13. Higley MJ, Sabatini BL. Competitive regulation of synaptic $\mathrm{Ca} 2+$ influx by $\mathrm{D} 2$ dopamine and A2A adenosine receptors. Nat Neurosci 2010; 13: 958-966.

14. Wang X, Zhong P, Gu Z, Yan Z. Regulation of NMDA Receptors by Dopamine D4 Signaling in Prefrontal Cortex. J Neurosci 2003; 23: 9852-9861.

15. Vaarmann A, Gandhi S, Gourine AV, Abramov AY. Novel pathway for an old neurotransmitter: dopamine-induced neuronal calcium signalling via receptor-independent mechanisms. Cell Calcium 2010; 48: 176-182.

16. Tang TS, Bezprozvanny I. Dopamine receptor-mediated $\mathrm{Ca} 2+$ signaling in striatal medium spiny neurons. J Biol Chem 2004; 279: 42082-42094.

17. Gandhi S, Vaarmann A, Yao Z, Duchen MR, Wood NW, Abramov AY. Dopamine induced neurodegeneration in a PINK1 model of Parkinson's disease. PLoS One 2012; 7: e37564.
18. Hartwick AT, Hamilton $\mathrm{CM}$, Baldridge WH. Glutamatergic calcium dynamics and deregulation of rat retinal ganglion cells. J Physiol 2008; 586: 3425-3446.

19. Stanika RI, Villanueva I, Kazanina G, Andrews SB, Pivovarova NB. Comparative impact of voltage-gated calcium channels and NMDA receptors on mitochondria-mediated neuronal injury. J Neurosci 2012; 32: 6642-6650.

20. Vaarmann A, Gandhi S, Abramov AY. Dopamine induces Ca2 + signaling in astrocytes through reactive oxygen species generated by monoamine oxidase. J Biol Chem 2010; 285: 25018-25023.

21. Surmeier DJ. Calcium, ageing, and neuronal vulnerability in Parkinson's disease. Lancet Neurol 2007; 6: 933-938.

22. Surmeier DJ, Ding J, Day M, Wang Z, Shen W. D1 and D2 dopamine-receptor modulation of striatal glutamatergic signaling in striatal medium spiny neurons. Trends Neurosci 2007; 30: 228-235.

23. Chinopoulos C, Adam-Vizi V. Calcium, mitochondria and oxidative stress in neuronal pathology. Novel aspects of an enduring theme. FEBS $J$ 2006; 273: 433-450.

24. Jekabsons MB, Nicholls DG. In situ respiration and bioenergetic status of mitochondria in primary cerebellar granule neuronal cultures exposed continuously to glutamate. J Biol Chem 2004; 279: 32989-33000.

25. Olney JW, Labruyere J, Wang G, Wozniak DF, Price MT, Sesma MA NMDA antagonist neurotoxicity: mechanism and prevention. Science 1991; 254: 1515-1518.

26. Chamoun R, Suki D, Gopinath SP, Goodman JC, Robertson C. Role of extracellular glutamate measured by cerebral microdialysis in severe traumatic brain injury. J Neurosurg 2010; 113: 564-570.

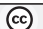

Cell Death and Disease is an open-access journal published by Nature Publishing Group. This work is licensed under the Creative Commons Attribution-NonCommercialShare Alike 3.0 Unported License. To view a copy of this license, visit http://creativecommons.org/licenses/by-nc-sa/3.0/

Supplementary Information accompanies the paper on Cell Death and Disease website (http://www.nature.com/cddis) 